\title{
In-Situ Measurement of Sensible Heat Ratio and Wetness Coefficient in Coal Mine Roadways
}

\author{
Jianliang Gao ${ }^{1,2,3}$, Jiajia Liu ${ }^{1,2,3}$, Quanfu $\mathrm{He}^{4}$ \\ ${ }^{1}$ The Collaborative Innovation Center of Coal Safety Production of Henan Province, Jiaozuo, China \\ ${ }^{2}$ State Key Laboratory Cultivation Base for Gas Geology and Gas Control, Jiaozuo, China \\ ${ }^{3}$ School of Safety Science and Engineering, Henan Polytechnic University, Jiaozuo, China \\ ${ }^{4}$ Longyan Seismological Bureau of Fujian Province, Lonyan, China \\ gao@hpu.edu.cn; liujiajia@hpu.edu.cn; hq111@163.com
}

\section{Extended Abstract}

The sensible heat ratio and wetness coefficient of roadway are important parameters for calculating the heat exchange between the wall of surrounding rock and air flow. Firstly, the variation pattern of sensible heat factor is analysed and illustrated theoretically. The sensible heat ratio decreases with the increase of the ventilation time after the rock surface is exposed, because of the decreasing of the surface temperature of the rock. The sensible heat ration increases with the enhancement of the relative humidity of airflow and decreases with the increase of the wetness coefficient of the rock surface. Secondly, according to the theory of heat and moisture exchange between mine air flow and surrounding rock, a method for calculating sensible heat ratio and wetness coefficient of underground roadway is proposed. The in-situ measurement has been carried out at several coal mines. The results show that the sensible heat ratio of rock roadway is larger than that of coal roadway, in which rock roadway is in the range of 0.4-0.7, coal roadway is in the range of 0.1-0.4, upper and lower hills are in the range of 0.2-0.4, and coal mining face is in the range of 0.1-0.4. For roadways with a small amount of water on the floor, the wetness coefficient is between 0.06 and 0.06 . For roadways with a small amount of water on the floor, the wetness coefficient is between 0.06 and 0.1 .

Keywords: Sensible heat, Latent heat, Sensible heat ratio, Wetness coefficient, In-situ measurement.

\section{References}

[1] S. Wu, Y. Wang, "Study on coefficient of heat transfer of tunnel wall," Uranium Mining and Metallurgy, vol. 8, no. 4, pp. 55-58, 1989.

[2] S. Wu, Y. Wang, "Study on of heat and mass transfer coefficients of wet tunnel walls," Journal of China Coal Society, vol. 18, no. 1, pp. 41-51, 1993.

[3] X. Zhou, Y. Sang, J. Wang, "Unstable heat transfer between surrounding rock and airflow in shaft," Journal of liaoning university of engineering technology, vol. 21, no. 3, pp. 264-266, 2002.

[4] Y. Guo, S. Wu, Mine Heat and Air Conditioning. Beijing: Coal industry Press, 1997.

[5] A.H. Sergey, Mine cooling guide. H. Huang Translation. Beijing: Coal industry Press, 1982.

[6] Y. Ceng and Q. Hou, Mine thermal environment engineering. Wuhai: Wuhan University of Technology Press, 1989.

[7] D. Yang and T. Yang, Mine thermal environment and its control. Beijing: Coal industry Press, 2009.

[8] J. Gao, B. Liu, "Field measurement method for thermal parameters of local ventilation tunneling face," Mining Safety \& Environmental Protection, vol. 31, no. 4, pp. 1-3, 2004.

[9] S. Yang, Z. Sun, H. Guo, "Analysis of thermal parameters and variation laws of air flow in Sanhejian high temperature mine," Jiangsu Coal, vol. 18, no. 3, pp. 41-43, 1995.

[10] F. Wang, L. Wang, B. Yu, "Determination of Thermal Parameters of Wind Turbine in High Temperature Mines and Its Change Law and Analysis of Thermal Wet Sources," Coal Mine Modernization, vol. 60, no. 3, pp. 51-53, 2004. 